\title{
iGENE: Aplicativo para identificação genômica de fungos filamentosos e leveduras
}

\author{
iGENE: Application for fillamentous and yeast genomic identification \\ iGENE: Aplicación para la identificación genómica de levaduras y filamentosas
}

Selena Dias Borborema Antunes ORCID: https://orcid.org/0000-0002-8685-3367 Universidade Estadual de Montes Claros, Brasil E-mail: selena.dba@gmail.com

Heveraldo Rodrigues de Oliveira ORCID: https://orcid.org/0000-0001-6593-1218 Universidade Estadual de Montes Claros, Brasil

E-mail: heveraldo.oliveira@unimontes.br

Marcos Flávio Silveira D'Angelo ORCID: https://orcid.org/0000-0001-5754-3397 Universidade Estadual de Montes Claros, Brasil mail: marcos.dangelo@unimontes.br

Mauro Aparecido de Sousa Xavier ORCID: https://orcid.org/0000-0002-0512-1616 Universidade Estadual de Montes Claros, Brasil E-mail: mauro.xavier@unimontes.br

Fabiana Brandão Alves Silva

ORCID: https://orcid.org/0000-0001-8358-8062 Universidade de Brasília, Brasil E-mail: fabianabrandao@unb.br

Dario Alves de Oliveira

ORCID: https://orcid.org/0000-0002-8161-4607 Universidade Estadual de Montes Claros, Brasil E-mail: dario.aol@gmail.com

Luciana Nobre Leite ORCID: https://orcid.org/0000-0003-1300-0897 Universidade Estadual de Montes Claros, Brasil E-mail: luciananl@msn.com Josiane dos Santos ORCID: https://orcid.org/0000-0002-7206-9627 Universidade Estadual de Montes Claros, Brasil E-mail: josianedsantos@yahoo.com.br

Frederico Santos Barbosa

ORCID: https://orcid.org/0000-0002-0353-6316 Universidade Estadual de Montes Claros, Brasil E-mail: frsb@novonordisk.com

Alessandra Rejane Ericsson de Oliveira Xavier ORCID: https://orcid.org/0000-0001-8558-4196 Universidade Estadual de Montes Claros, Brasil E-mail: alessandra.ericsson@unimontes.com

\begin{abstract}
Resumo
Inovações em metodologias para identificação de microrganismos genômicas e proteômicas associadas a tecnologias digitais estão em alinhamento com a visão de indústria 4.0 e estão em ascensão. $\mathrm{O}$ objetivo desse trabalho foi o desenvolvimento de um protótipo de um aplicativo (App) para a identificação de fungos filamentosos e leveduras ao nível de espécie. A construção do protótipo foi realizada de modo a apresentar uma aplicação web com interface responsiva. O App foi desenvolvido em processo cloud computing com modelo em cascata. Como parte dos requisitos do App foi construído um banco de dados Cloud Firestore com processamento de imagens através de uma biblioteca skImage. Para tal, foram selecionados géis de agarose com perfis de restrição de fungos filamentosos e leveduras previamente identificados ao nível de espécie por metodologias genômicas (PCR/RFLP) e proteômica (espectrometria de massa). O App identificado como iGENE foi capaz de realizar o reconhecimento de perfis de restrição de géis de agarose, comparando-o aos fungos filamentosos e leveduras cadastrados em sua biblioteca. O resultado ao nível de espécie foi possível para perfis com similaridade superior a 90\%. Embora as imagens analisadas tenham apresentado esse perfil, o App foi construído de modo a considerar também identificações ao nível de gênero para similaridades entre 89 e 70\%, bem como "microrganismo não identificado" abaixo desse escore. A inclusão de novas espécies de
\end{abstract}


fungos filamentosos e leveduras na biblioteca do App permitirá uma maior robustez na geração do resultado da identificação ao nível de espécie.

Palavras-chave: Biotecnologia; Visão computacional; Processamento de imagem; Identificação de microrganismos; Perfil de restrição; Biblioteca.

\begin{abstract}
Innovations in genomic and proteomic methodologies for identification of microrganisms associated with digital technologies are in alignment with Industry 4.0 vision and are increasing. The objective of this work was to develop a prototype of an application (App) for the identification of filamentous fungi and yeasts at the species level. The construction of the prototype was carried out in order to present a web application with a responsive interface. The App was developed using a cloud computing process with a cascade model. As part of the App's requirements, a Cloud Firestore database was built with image processing through a skImage library. For this purpose, agarose gels with filamentous fungi and yeasts restriction profiles previously identified at the species level by genomic (PCR/RFLP) and proteomic (mass spectrometry) methodologies were selected. The App identified as iGENE was able to perform the recognition of restriction profiles of agarose gels, comparing it to the filamentous fungi and yeasts registered in its library. The result at the species level was possible for profiles with more than $90 \%$ similarity. Although the analyzed images presented this profile, the App was built in order to also consider identifications at the genus level for similarities between 89 and 70\%, as well as "unidentified microorganism" below this score. The inclusion of new filamentous fungi and yeasts species in the App library will allow for greater robustness in the generation of the identification result at the species level.
\end{abstract}

Keywords: Biotechnology; Computer vision; Image processing; Identification of microorganisms; Library.

\title{
Resumen
}

Las innovaciones en las metodologías para la identificación de microorganismos genómicos y proteómicos asociados a las tecnologías digitales están en línea con la visión de la industria 4.0. El objetivo de este trabajo fue desarrollar un prototipo de aplicación (App) para la identificación de hongos filamentosos y levaduras a nivel de especie. La construcción del prototipo se realizó para presentar una aplicación web con una interfaz receptiva. La aplicación fue desarrollada en cloud computing con un modelo en cascada. Como parte de los requisitos de la aplicación, se creó una base de datos de Cloud Firestore con procesamiento de imágenes a través de una biblioteca skImage. Para ello, se seleccionaron geles de agarosa con perfiles de restricción de hongos filamentosos y levaduras previamente identificadas a nivel de especie mediante metodologías genómicas (PCR / RFLP) y proteómicas (espectrometría de masas). La aplicación identificada como iGENE pudo reconocer perfiles de restricción de geles de agarosa, comparándolo con hongos filamentosos y levaduras registrados en su biblioteca. El resultado a nivel de especie fue posible para perfiles con más del $90 \%$ de similitud. Si bien las imágenes analizadas presentaban este perfil, la App fue construida para considerar también identificaciones a nivel de género para similitudes entre 89 y $70 \%$, así como "microorganismos no identificados" por debajo de esta puntuación. La inclusión de nuevas especies de hongos filamentosos y levaduras en la librería de la App permitirá una mayor robustez en la generación del resultado de identificación a nivel de especie.

Palabras clave: Biotecnología; Visión por computador; Procesamiento de imágenes; Identificación de microorganismos; Perfil de restricción; Biblioteca.

\section{Introdução}

A biotecnologia se fundamenta em conhecimentos multidisciplinares e pode ser analisada a partir de dimensões científicas e a tecnológicas, sendo que a dimensão científica se refere à pesquisa considerada básica, que inclui a biologia molecular, microbiologia e genética, já a dimensão tecnológica está relacionada à pesquisa de como converter esses estudos em aplicações industriais e comerciais (Sayuri et al., 2020). Atualmente, há novas tecnologias que representam inovações relacionados à Indústria 4.0, as quais envolvem, dentre outras, inovações biológicas (biotecnologia e genética), que estão interligadas às tecnologias digitais e que dão suporte para o avanço da biotecnologia (Lima \& Gomes, 2020).

Conforme descrito por Lima et al. (2019), vivemos a quarta revolução industrial, a qual considera a utilização de tecnologias digitais com o objetivo de desenvolver novos produtos. Dentre as tecnologias existentes, é possível utilizar tecnologias de Visão Computacional, que estão relacionadas a técnicas de processamento de imagens e que consideram algoritmos computacionais no processamento de imagens digitalizadas (Feliciano et al., 2010), sendo que este pode ser considerado como um exemplo da dimensão tecnológica da biotecnologia. Além disso, a Inteligência Artificial (IA), que é uma ciência cognitiva com pesquisas nas áreas de processamento de imagens, trata-se de uma tecnologia disruptiva e diretamente 
relacionada às tecnologias da quarta revolução industrial (Telles et al., 2020). A IA é uma das principais tecnologias envolvidas na Indústria 4.0, que a possui como um dos pilares, dentre outros. Além de trabalhar em menor tempo, maior velocidade e com menor custo, este tipo de tecnologia pode atuar na resolução de problemas e essas tecnologias digitais formam as bases para a transformação da Indústria 4.0 (Teixeira et al., 2019, p.28290-28309; Ronaldo Albertin et al., 2017).

A metodologia para identificação de microrganismos, que é escopo da dimensão científica da biotecnologia, pode ser classificada através de duas categorias, sendo a primeira relacionada à análise fenotípica dos microrganismos e a segunda está relacionada às características genotípicas, que contemplam os genes e ácidos nucléicos que constituem os microrganismos (Nobre et al., 2020).

Dentre métodos utilizados para a identificação de microrganismos, o método molecular PCR-RFLP é baseado nas variações da sequência de DNA presentes nos padrões de bandas eletroforéticas após a digestão por enzimas de restrição. Trata-se de um método cuja execução é simples, é econômico, além de ser rápido (Santos et al., 2019). Ainda com relação à identificação de microrganismos, a espectrometria de massa por MALDI-ToF (Matrix Assisted Laser Desorption Ionization Time of Flight), é um dos métodos de espectrometria de massa mais utilizados, que pode ser utilizado em combinação com outros métodos e que é uma metodologia utilizada que utiliza proteínas ribossomais das células dos microrganismos (Tsuchida et al., 2020).

Ainda que haja inúmeras metodologias para identificação de microrganismos, há a necessidade contínua para o desenvolvimento de novas metodologias (Chaves Moreira \& Rene S. M. Souza, 2020). Por exemplo, existem limitações na espectrometria de massa por MALDI-ToF, cujo sistema possui bancos de dados pertencente à proprietários específicos e que necessita da atualização da biblioteca para que seja realizada a identificação ao nível de espécie de determinados microrganismos, como fungos filamentosos (Barbosa et al., 2021, p. 58556-58574).

Portanto, é possível utilizar tecnologias para o desenvolvimento de um software para o processo de identificação de microrganismos. Através deste software é possível fotografar o perfil de restrição de DNA e ter como resultado a identificação genômica do microrganismo em questão, eliminando a etapa de sequenciamento genético necessária no processo convencional. Foi realizada consulta em bancos de patentes e não foi encontrado nenhum registro relacionado à software para identificação de microrganismos baseado na imagem de perfil de restrição de fungos e leveduras filamentosos gerados por PCR/RFLP da região universal fúngica (18S rDNA, 5,8S rDNA, 28S rDNA, ITS1 e ITS2). O objetivo este trabalho foi desenvolver um aplicativo para identificação genômica de fungos filamentosos e leveduras ao nível de espécie.

\section{Metodologia}

\subsection{Design e requisitos computacionais do aplicativo}

O processo de desenvolvimento do aplicativo foi baseado no modelo em cascata descrito em Sommerville, I. (2011). As atividades envolveram a especificação do software, projeto, implementação e validação.

\subsubsection{Especificação do Software}

A especificação do software foi feita com base em uma reunião com stakeholders e resultou na seguinte lista de requisitos:

- Cadastro de Análises em Laboratório

- Cadastro e Carregamento de Foto de Gel de Agarose

- Processamento da Imagem do Gel para Reconhecimento dos Fragmentos

- Ajustamento pelo analista dos Fragmentos Detectados

- Identificação dos Microrganismos pela Busca de Similaridades no Banco de Dados 
- Registro de Novo Microrganismo não Encontrado no Banco de Dados

- Cadastro de Marcadores de Massa Molecular

- Cadastro de Enzimas de Restrição

O diagrama de casos de uso da Figura 1 representa os requisitos do aplicativo. As funcionalidades de Inserir Novo Microrganismo, Cadastrar Marcadores e Cadastrar Enzimas foram especificadas como restritas ao usuário “Administrador".

Figura 1. Diagrama de Casos de Uso do Aplicativo iGENE.

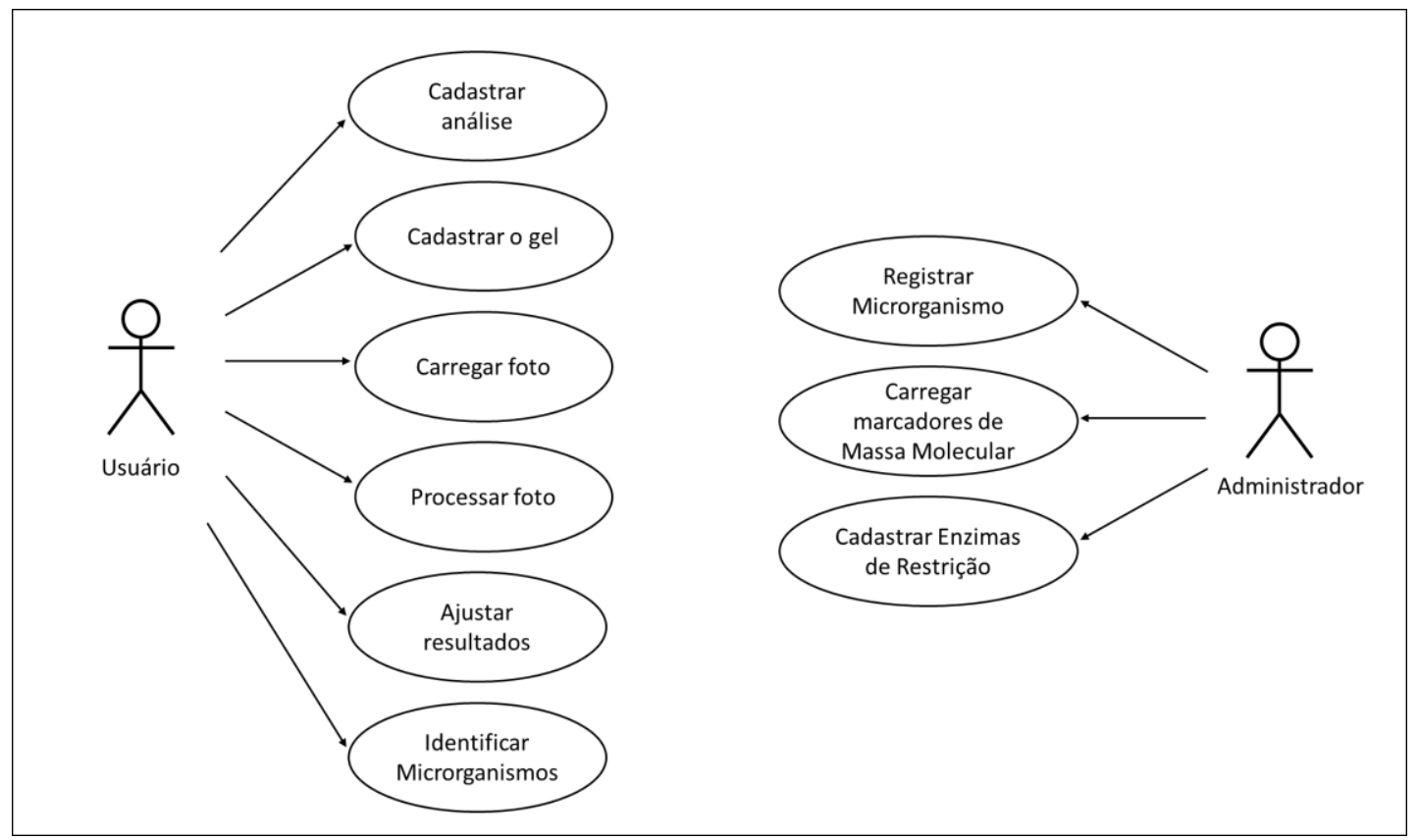

Fonte: Autores.

Para confirmar que os requisitos especificados seriam atendidos pelo aplicativo, foi confeccionado um modelo conceitual de dados no formato ER (Entidade-Relacionamento), como descrito em Elmasri e Navathe (2011).

\subsubsection{Projeto e Implementação}

Para evitar processos de instalação, contratação de lojas de aplicativos e dependências relacionadas ao hardware e software do dispositivo do usuário, além da limitação de poder de processamento local, a opção definida foi através do desenvolvimento em cloud computing. O aplicativo foi desenvolvido como uma aplicação web com interface responsiva (utilizável em múltiplos dispositivos, ou seja, em desktop, smartphone, TV, etc.) e processamentos assíncronos, necessitando apenas de um navegador atualizado. Dentre as várias opções de cloud computing disponíveis, o Google Cloud nos despertou grande interesse devido à usabilidade, preços, variedade de recursos e facilidade de configuração. O App Engine, como é chamada a plataforma gerenciada como serviço do Google (PaaS, na sigla em inglês), cuida do gerenciamento da infraestrutura de suporte e possui vários recursos que favorecem a escalonabilidade, o balanceamento de carga, a geração de registros, o monitoramento e a segurança, além de permitir a programação em várias linguagens e o uso de diferentes serviços (Google. (2021, July 16)).

O banco de dados Cloud Firestore é indicado pelo Google para aplicações móveis e Web, pela facilidade de implementação, atualizações e consultas, escalonabilidade e acesso global. Por ser um banco de dados NoSQL, que é utilizado para suprir necessidade de armazenamento e processamento de grandes volumes de dados (Rockenbach et al., 2018), os dados 
foram organizados em coleções de documentos: Análises, Géis, Poços, Marcadores de massa molecular, Registros e Microrganismos. Outras tecnologias utilizadas na implementação do aplicativo foram: Python, Flask, Bootstrap, HTML5, CSS, JavaScript, JSON, Numpy, VsCode e OAuth 2.0. Estas tecnologias compõem o aplicativo, desde sua estruturação e arquitetura, até a segurança de acesso, funcionalidades para login e logout e permissões de acesso para cada grupo de usuário, tornando-o mais robusto. Além disso, há tecnologias relacionadas a bibliotecas complementares, que possibilitam a obtenção de um aplicativo funcional para o objeto do presente estudo.

\subsubsection{Processamento Digital das Fotos de Gel de Agarose}

As fotos dos géis de agarose carregadas são armazenadas no Google Cloud Storage. O processamento é feito com a biblioteca skImage. Para melhor performance no processamento, as imagens são reduzidas em resolução para 500 linhas de pixels, mantendo a proporção para a largura.

Uma primeira abordagem usando limiarização, como em Rosa (2011) ou em Soares (2010), não produziu resultados satisfatórios para as fotos disponíveis, principalmente por não detectar os fragmentos menos nítidos. Uma implementação usando a função Template Matching é proposta aqui, sendo que Template matching é a tarefa de executar uma correlação entre duas imagens, sendo uma delas chamada de template e a outra é a imagem do campo de busca. O objetivo é encontrar a ocorrência do template na imagem maior (Cole, Austin, \& Cole, 2004). No nosso caso, o algoritmo deve encontrar as ocorrências de bandas de fragmentos de eletroforese em uma foto de gel de agarose. A função template matching é sensível ao tamanho do template, isto é, o template deve ser do mesmo tamanho da ocorrência na imagem do campo de busca. Para resolver o problema, uma função de contornos da biblioteca skImage foi utilizada para encontrar contornos que representassem bandas de fragmentos. Um contorno com largura de 2.5 vezes ou mais vezes da altura pareceu razoável para identificar uma banda nítida. O template é então redimensionado para o tamanho do contorno encontrado.

As trilhas são detectadas automaticamente pelo alinhamento médio das bandas de acordo com os centros reportados pelo template matching e pelo tamanho do template utilizado. Caso o centro encontrado esteja na área (horizontalmente) de outra banda encontrada, estas são colocadas na mesma trilha e o centro médio entre todas as bandas da trilha é calculado. As bandas detectadas são alinhadas pelo centro médio para formar as trilhas. Algumas bandas são falso positivas e a sensibilidade foi ajustada para evitar falsos negativos. Essa decisão foi tomada com base na definição dos stakeholders, que optaram pela detecção de fragmentos menos nítidos, o que ocasionam a detecção, também, de pequenas manchas no gel como se fossem fragmentos, os falsos positivos.

Várias limitações na detecção das bandas e das trilhas são reportadas na literatura, como por exemplo: deformação do gel, contraste da imagem, manchas e rachaduras no gel (Oliveira, 2012). Para complementar o processo, foi adicionado ao aplicativo uma etapa de ajuste manual pelo usuário. Nesta etapa o usuário pode excluir bandas detectadas erroneamente (falsos positivos) ou incluir bandas não detectadas (falsos negativos).

\subsubsection{O Processo de análise auxiliado pelo aplicativo}

O processo da análise do aplicativo por foto do perfil de PCR/RFLP está representado na Figura 2. Primeiramente o usuário deve cadastrar o gel de agarose informando um identificador e o amplicon correspondente em pb (pares de base). O processo deve prosseguir pela escolha do arquivo da foto do gel, para carregamento e armazenamento do storage do iGENE na nuvem. Após o carregamento da foto, o usuário solicita o processamento digital da imagem, sendo que esta etapa é responsável pela realização do reconhecimento automático das bandas de fragmentos na imagem. No próximo passo são disponibilizadas ferramentas para ajustes manuais nas bandas detectadas e o cadastramento das informações dos poços do gel de agarose. Depois dos ajustes, o cálculo dos fragmentos pode ser executado. No último passo, uma pesquisa no banco de dados é 
executada com o objetivo de, através da similaridade entre os valores calculados na imagem e no perfil de fragmentos previamente cadastrados nos registros de microrganismos, identificar a espécie no material analisado.

Figura 2. Fluxo do Processo de Análise Auxiliado pelo Aplicativo.
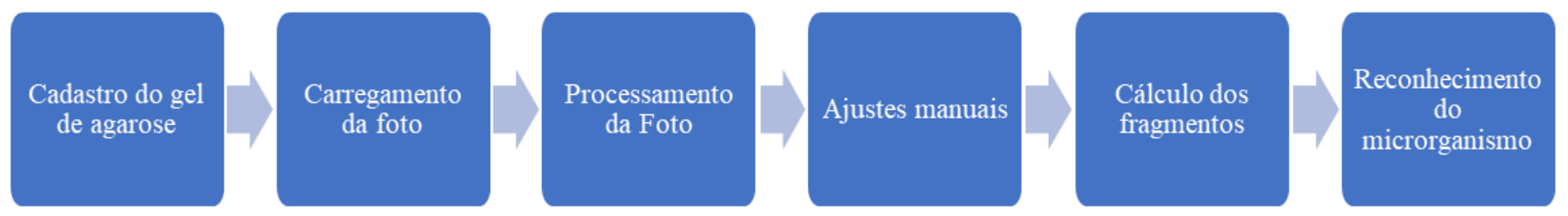

Fonte: Autores.

\subsection{Construção da biblioteca com perfis genômicos de fungos filamentosos e leveduras}

Foram selecionados perfis de restrição de fungos e leveduras filamentosos gerados por PCR/RFLP da região universal fúngica (18S rDNA, 5,8S rDNA, 28S rDNA, ITS1 e ITS2), previamente descritos e gentilmente cedidos por gentilmente cedidos por Santos et al. (2019) e Nobre et al. (2020) para este trabalho. Dentre os critérios para inclusão de amostras na biblioteca genômica do aplicativo estiveram: fungos filamentosos e leveduras identificadas ao nível de espécie pelo método MALDI-ToF. Para tal, foram selecionados os perfis de restrição dos fragmentos de restrição de 2000pb (região universal fúngica) digeridos com as enzimas de restrição BsuRI e Taq ${ }^{\alpha} 1$ (Santos et al., 2019; Nobre et al., 2020). Foram excluídos aqueles microrganismos identificados somente ao nível de gênero, bem como aqueles cujo perfil não apresentou resolução nítida no gel de agarose. Os microrganismos selecionados para inclusão na biblioteca genômica do aplicativo foram: Candida guilliemondi, Candida rugosa, Candida krusei, Candida albicans, Aspergillus versicolor e Rhodoporidium toruloides. O quadro 1 exibe a lista de microrganismos registrados no aplicativo iGENE. Um registro é composto pelo nome do microrganismo, uma identificação de tipo, uma enzima utilizada, um valor de amplicon e a sequência de valores do perfil de fragmentos.

Quadro 1. Fungos filamentosos e leveduras cadastrados na biblioteca do Aplicativo iGENE.

\begin{tabular}{|c|c|c|c|c|}
\hline Nome & Tipo & Enzima & Amplicon(pb) & Fragmentos (pb) \\
\hline Aspegillus versicolor & Fungo & BsuRI & 2000 & 450,600 \\
\hline Aspegillus versicolor & Fungo & Taq $\alpha 1$ & 2000 & $140,200,310,350,400,500$ \\
\hline Candida albicans & Fungo & BsuRI & 2000 & $225,300,400,550$ \\
\hline Candida albicans & Fungo & Taq $\alpha 1$ & 2000 & $140,200,500$ \\
\hline Candida guilliermondii & Fungo & BsuRI & 2000 & $120,140,400,500,610$ \\
\hline Candida guilliermondii & Fungo & Taq $\alpha 1$ & 2000 & $140,200,300,400,500$ \\
\hline Candida krusei & Levedura & BsuRI & 2000 & $50,125,250,290,390,550$ \\
\hline Candida rugosa & Levedura & BsuRI & 2000 & $100,140,500,800$ \\
\hline Rhodosporidium toluroides & Levedura & BsuRI & 2000 & $400,550,610$ \\
\hline Rhodosporidium toluroides & Levedura & Taq $\alpha 1$ & 2000 & $140,160,210,390,500,600$ \\
\hline
\end{tabular}

Fonte: Autores.

\section{Resultados e Discussão}

Métodos utilizados para identificação de microrganismos têm sido descritos na literatura, dentre os quais aqueles baseados em genômica e proteômica (Santos et al., 2019, Nobre et al., 2020, Tsuchida et al., 2020, Zhu et al., 2020). Entretanto, limitações em relação ao uso de método proteômico baseado em espectrometria de massa na identificação de microrganismos ao nível de espécie estão descritos na literatura (Xavier et al., 2019, Nobre et al., 2020, Fernandes et al., 2020). Em determinados casos, é necessário estabelecer protocolos de preparação de amostras, para assegurar a destruição física das 
paredes celulares para se obter a identificação ao nível de espécie de fungos filamentosos e, além disso, a identificação incorreta ou a não identificação de gêneros e espécies de fungos filamentosos também pode ser causada por erros, ausências ou espectros de referência incompletos nos bancos de dados do MALDI-ToF. (Tsuchida et al., 2020).

Métodos genômicos baseados em análise de polimorfismo por PCR/RFLP têm revelado eficiência na identificação de fungos e leveduras ao nível de espécie (Kordalewska et al., 2018, Robledo-Leal et al., 2018, Santos et al., 2019, Nobre et al., 2020). Neste sentido, foi elaborado um aplicativo com o objetivo de proporcionar a identificação de fungos filamentosos e leveduras ao nível de espécie integrando metodologias genômicas, proteômicas e inteligência artificial. A Figura 3 descreve um esquema geral com as etapas analíticas requeridas para identificação de fungos e leveduras pelo aplicativo identificado com o nome de iGENE. As etapas requeridas são mostradas na Figura 3 nos passos 1 a 5 .

Aplicativos para identificação de microrganismos têm sido descritos na literatura (Wang et al., 2019). Entretanto, é de nosso conhecimento que este é o primeiro App com sistema de reconhecimento de imagem baseado na leitura do perfil de PCR/RFLP, análise e comparação com banco de dados (biblioteca de perfis genômicos) para geração de um índice de identificação de fungos filamentosos e leveduras ao nível de espécie.

Figura 3. Esquema geral do aplicativo iGENE.

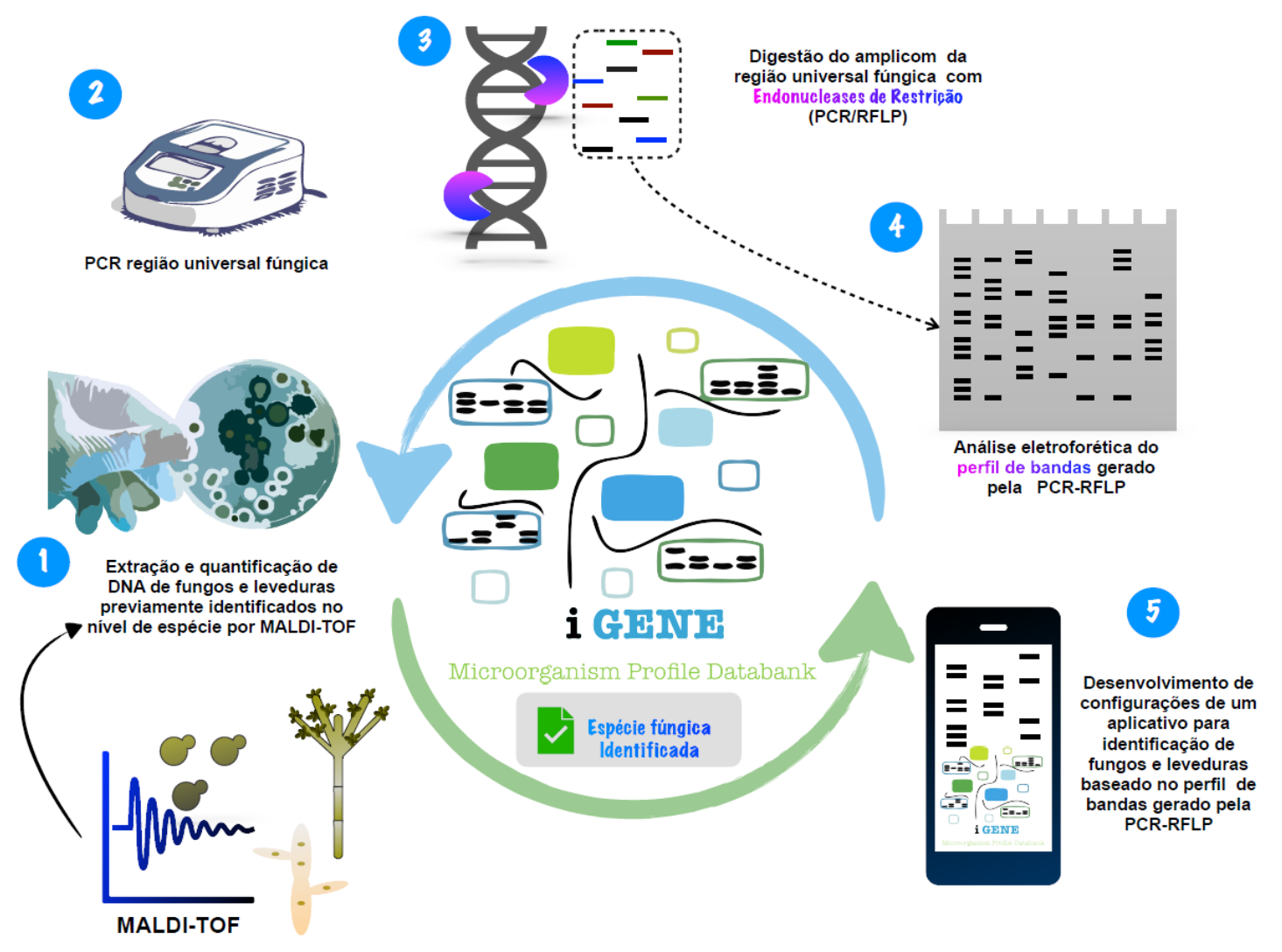

Fonte: Autores.

\subsection{Interfaces do Aplicativo}

As interfaces do aplicativo foram desenvolvidas em HTML5, CSS e JavaScript usando um modelo do Bootstrap. A Figura 4 mostra a tela principal com uma sidebar, uma topbar, um ícone de login no canto superior direito. A sidebar representa o menu de opções de acesso às funcionalidades disponíveis. A opção "Análise" permite cadastrar os géis de agarose, carregar as fotos e demais funcionalidades de reconhecimento dos microrganismos. A opção "Microrganismos" disponibiliza a consulta e correção dos registros já inseridos, bem como o cadastro básico de microrganismos. Já as opções de "Marcadores" e 
"Enzimas" são apenas para cadastros dos respectivos marcadores de massa molecular e enzimas de restrição utilizados.

Figura 4. Tela Principal do Aplicativo iGENE.
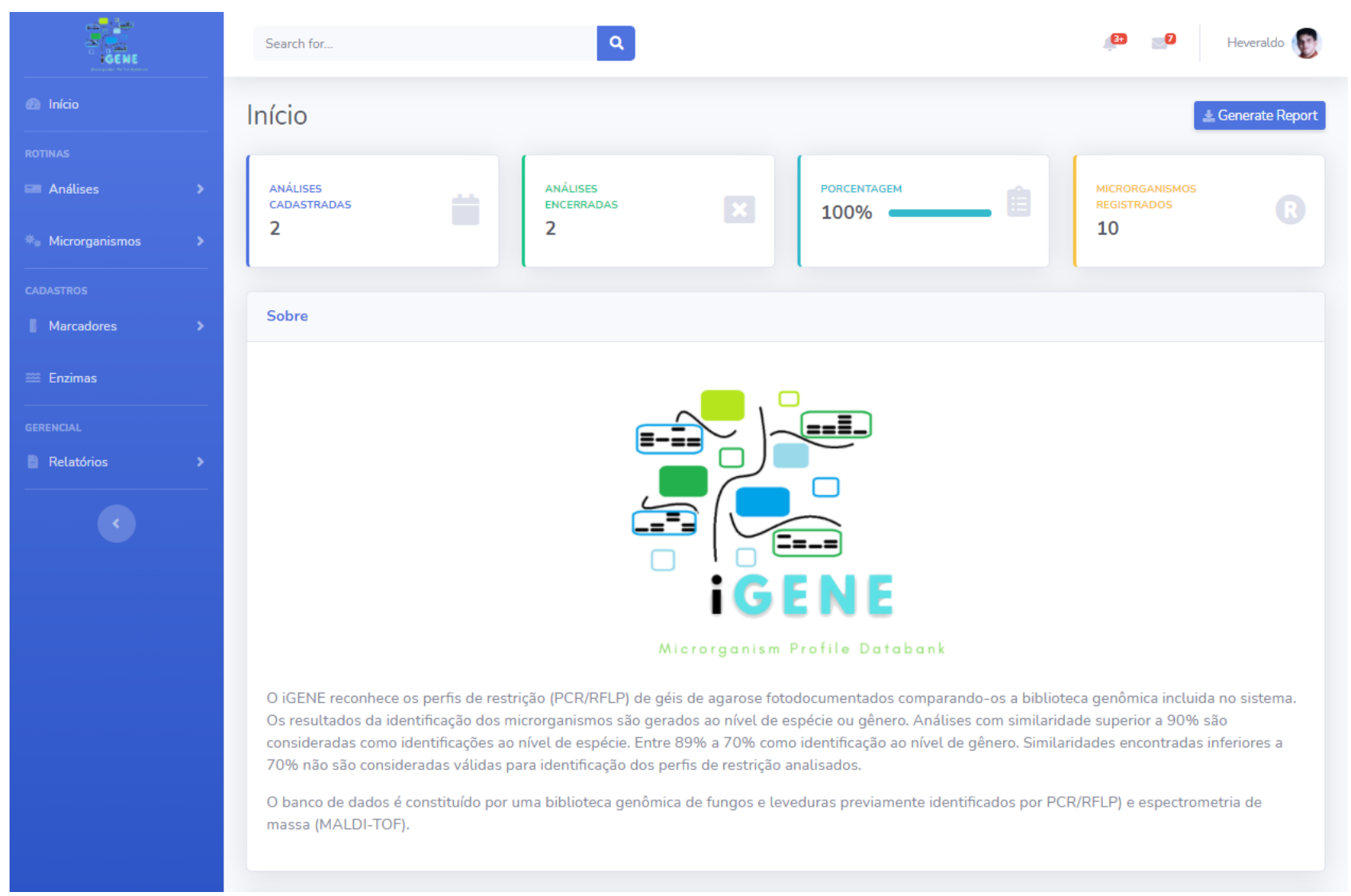

Fonte: Autores.

\subsection{Validação do aplicativo}

As fotos dos géis de agarose foram carregadas e processadas no aplicativo iGENE. O gel processado, cedido por Nobre et al. (2020) é apresentado na Figura 5. Na Figura 5a é exibida a foto do gel carregada no aplicativo. A Figura 5b mostra o resultado do processamento para identificação automática dos fragmentos. Na Figura 5c aparece a imagem com as marcas de fragmentos ajustadas pelo usuário. A Figura 5d apresenta os valores já calculados para cada fragmento. Finalmente, na Figura 5e podemos visualizar o resultado da busca por espécies de microrganismos com perfil de fragmentos similar no banco de dados de registros do aplicativo. Como resultado, são apresentados o nome do microrganismo, os fragmentos constantes do registro e a similaridade calculada em porcentagem. Os poços são numerados pela posição da esquerda para a direita. Apenas microrganismos com $90 \%$ ou mais de similaridade são visualizados, enquanto a expressão "Não Identificado" é apresentada caso não sejam encontrados microrganismos similares do banco de dados. O aplicativo demonstrou capacidade de processar tanto fotos com fundo escuro, quanto fotos com fundo claro. 
Research, Society and Development, v. 11, n. 2, e13011225103, 2022

(CC BY 4.0) | ISSN 2525-3409 | DOI: http://dx.doi.org/10.33448/rsd-v11i2.25103

Figura 5. Etapas do Processamento do Gel de Agarose mostrando o perfil de bandas digeridos com enzimas de restrição 1. a) Foto carregada. b) Foto processada pelo iGENE. c) Foto com ajustes manuais. d) Foto com valores dos fragmentos calculados. e) Resultado da Tela do aplicativo com o resultado da busca por similaridades.

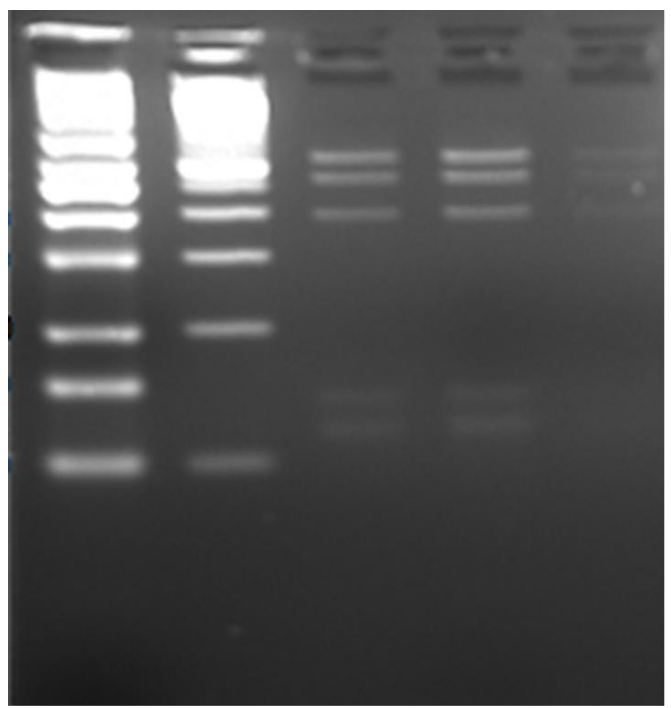

(a)

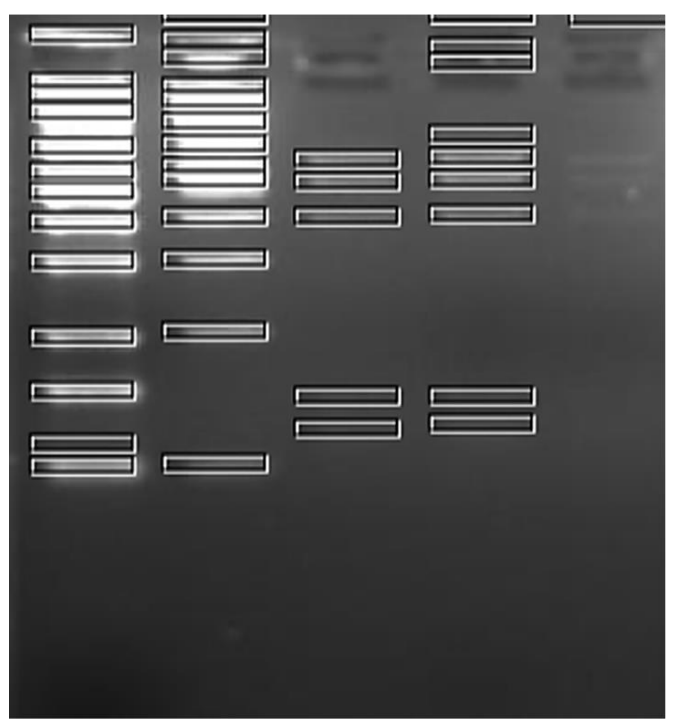

(c)

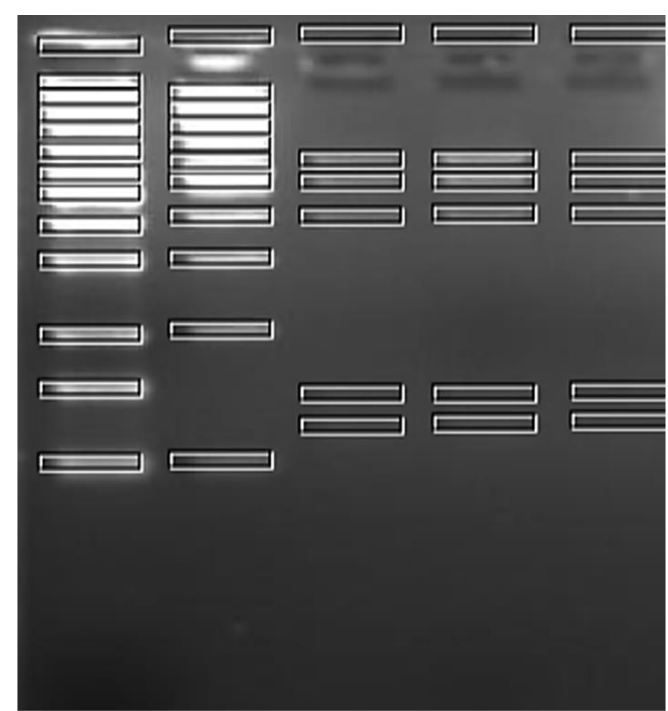

(b)

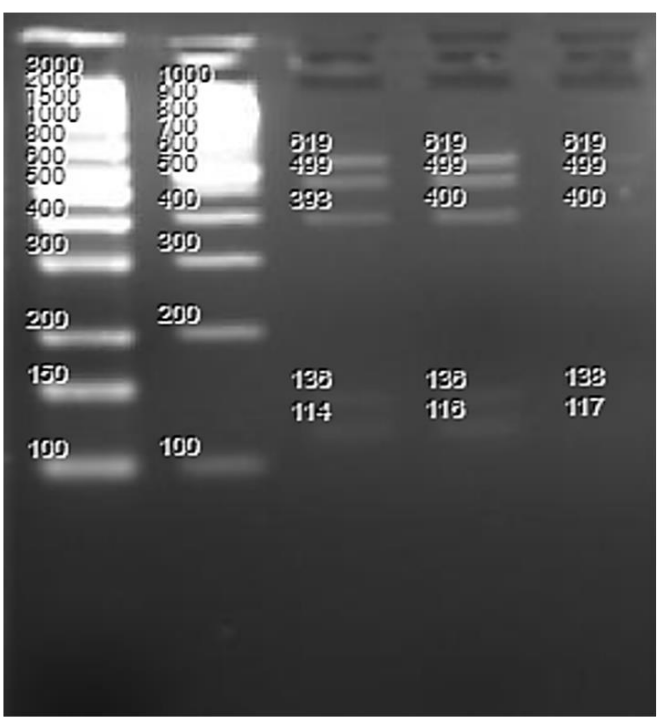

(d)

\begin{tabular}{|l|l|l|l|l|}
\hline Poço & Microrganismo & Fragmentos do Registro & Similaridade & Ação \\
\hline 1 & Marcador & Mid Range DNA Ladder & N/A & N/A \\
\hline 2 & Marcador & GeneRuler 100 bp DNA Ladder & N/A & Confirmar \\
\hline 3 & Candida guilliermondii & $120,140,400,500,610$ & $98.5 \%$ & $99.0 \%$ \\
\hline 5 & Candida guilliermondii & $120,140,400,500,610$ & Confirmar \\
\hline 5 & Candida guilliermondii & $120,140,400,500,610$ & $99.2 \%$ & Confirmar \\
\hline
\end{tabular}

(e)

Fonte: Autores. 


\section{Conclusão}

Através do trabalho realizado no iGENE, evidenciou-se que foi possível utilizar uma aplicação web com interface responsiva e desenvolvida em cloud computing, contendo uma biblioteca que contém imagens de géis de agarose contendo perfis de restrição de fungos filamentosos e leveduras, identificados previamente por metodologias genômicas e proteômicas. As etapas de validação demonstraram a funcionalidade do aplicativo em executar as etapas de carregamento, processo da imagem e geração de um resultado com perfil de similaridade para espécie, gênero ou "microrganismos não identificados".

Todos os microrganismos submetidos à identificação apresentaram resultados coincidentes com os esperados e demonstrando que o aplicativo atua conforme proposto. Portanto, o iGENE demonstrou alinhamento à aplicação de conceitos biotecnológicos que estão diretamente relacionados às novas inovações tecnológicas da indústria 4.0.

Trata-se de um aplicativo inovador, que utiliza tecnologias de inteligência artificial e metodologias para identificação de microrganismos. Como este trabalho possui caráter de inovação, foi realizada uma consulta em bancos de patentes e não foi encontrado nenhum registro relacionado à software com o mesmo propósito do iGENE. Portanto, este é o primeiro aplicativo com sistema de reconhecimento de imagem baseado na leitura do perfil de PCR/RFLP, análise e comparação com banco de dados (biblioteca de perfis genômicos) para geração de um índice de identificação de fungos filamentosos e leveduras ao nível de espécie. Esta informação se baseia em busca realizada na literatura, em agosto de 2021, nas bases de dados do NCBI através da plataforma PubMed, no SciELO e LILACS.

Para trabalhos futuros, como aplicativo apresenta limitações na detecção das bandas e que requerem ajustes realizados pelo usuário de forma manual, o mesmo pode ser aprimorado para minimizar estas intervenções humanas. Além disso, o banco de dados atualmente considera apenas fungos filamentosos e leveduras, é esperado que este banco de dados seja ampliado, para esteja apto a realizar a identificação em nível de outros tipos de microrganismos.

\section{Agradecimentos}

Programa de Pós-Graduação em Biotecnologia (PPGB) da Universidade Estadual de Montes Claros, Minas Gerais, Brasil, pelo Departamento de Ciências da Computação do Centro de Ciências Exatas e Tecnológicas (CCET) da Universidade Estadual de Montes Claros, Minas Gerais, Brasil e Novo Nordisk Produção Farmacêutica do Brasil.

\section{Referências}

A. Rockenbach, D., Anderle, N., Griebler, D., \& Souza, S. (2018). Estudo Comparativo de Bancos de Dados NoSQL. Revista Eletrônica Argentina-Brasil ne Tecnologias na Informação e da Comunicação, 1(8), http://dx.doi.org/10.5281/zenodo.1228503.

Barbosa, Kevin Haley et al. Impacto do MALDI-TOF no diagnóstico da Sepse: uma revisão integrativa / Impact of MALDI-TOF in the diagnosis of Sepsis: an integrative review. Brazilian Journal of Development, 7(6), 58556-58574, https://doi.org/10.34117/bjdv7n6-313.

Cole, L., Austin, D., \& Cole, L. (2004). Visual object recognition using template matching. In Australian conference on robotics and automation.

Chaves Moreira, T., \& Rene S. M. Souza, M. (2020). O uso da espectrometria de massa maldi tof na identificação de microrganismos para diagnóstico laboratorial. Revista Eletrônica Biociências, Biotecnologia e Saúde, 12(24), 53-59. https://interin.utp.br/index.php/GR1/article/view/2445/2047

Ericsson de Oliveira Xavier, A. R., Cardoso, L., Brito, R. V. J., Nobre, S. A. M., De Almeida, A. C., Ericsson de Oliveira, A. M., \& De Sousa Xavier, M. A. (2019). Detection and identification of medically important microorganisms isolated from pigeon excreta collected in a university in a newly industrialized country. Biotemas, 32(1), 11-20. https://doi.org/10.5007/2175-7925.2019v32n1p11

Elmasri, R., \& Navathe, S. B. (2011). Sistemas de Banco de Dados (6th ed.). Person Addison Wesley.

Feliciano, F. F., Souza, I. L. d., \& Leta, F. R. (2010). Visão computacional aplicacada à metrologia dimensional automatizada: considerações sobre sua exatidão. Engevista, 7(2). https://doi.org/10.22409/engevista.v7i2.164

Fernandes, L. F., Souza, G. Á. A. D., Almeida, A. C. d., Cardoso, L., Xavier, M. A. d. S., Pinheiro, T. P. P., Cruz, G. H. S. d., Dourado, H. F. S., Silva, W. S., \& Xavier, A. R. E. d. O. (2020). Identification and characterization of methicillin-resistant Staphylococcus spp. isolated from surfaces near patients in an intensive care unit of a hospital in southeastern Brazil. Revista da Sociedade Brasileira de Medicina Tropical, 53. https://doi.org/10.1590/0037-8682-02442020 
Google. (2021, July 16). Como exibir sites. Centro de arquitetura do Cloud. https://cloud.google.com/architecture/web-serving-overview?hl=pt_br\#app-engine

Kordalewska, M., Kalita, J., Bakuła, Z., Brillowska-Dąbrowska, A., \& Jagielski, T. (2018). PCR-RFLP assays for species-specific identification of fungi belonging to Scopulariopsis and related genera. Medical Mycology, 57(5), 643-648. https://doi.org/10.1093/mmy/myy106

Lima, F. R., \& Gomes, R. (2020). Conceitos e tecnologias da indústria 4.0. Revista Brasileira de Inovação, 19, Artigo e0200023. https://doi.org/10.20396/rbi.v19i0.8658766

Luciana Nobre, L., Felipe José Nobre, L., Mauro Aparecido, d. S. X., Josiane, d. S., Leia, C., Frederico Santos, B., Rosimar Fonseca, d. S., Soraia Aparecida Maia, D., \& Alessandra Rejane Ericsson, d. O. X. (2020). Molecular identification and characterization of filamentous fungi and yeasts isolated in a pharmaceutical industry environment. Journal of Applied Pharmaceutical Science. https://doi.org/10.7324/japs.2020.10704

Oliveira, M. A. L., Lago, C. L. d., Tavares, M. F. M., \& Silva, J. A. F. d. (2003). Análise de ácidos graxos por eletroforese capilar utilizando detecção condutométrica sem contato. Química Nova, 26(6), 821-824.

Robledo-Leal, E., Rivera-Morales, L. G., Sangorrín, M. P., González, G. M., Ramos-Alfano, G., Adame-Rodriguez, J. M., Alcocer-Gonzalez, J. M., ArechigaCarvajal, E. T., \& Rodriguez-Padilla, C. (2018). Identification and susceptibility of clinical isolates of Candida spp. to killer toxins. Brazilian Journal of Biology, 78(4), 742-749. https://doi.org/10.1590/1519-6984.175635

Ronaldo Albertin, M., Luiza Bufalari Elienesio, M., dos Santos Aires, A., Lopes Jaguaribe Pontes, H., \& Pinheiro Aragão, D. (2017). Principais inovações tecnológicas da Indústria 4.0 e suas aplicações e implicações na manufatura. In XXIV Simpósio de Engenharia se Produção.

Rosa, M. A. da, Brun, A. L., \& Kiel, G. (2011). Ferramenta Multiplataforma para Construção Automática de Dendogramas a partir de Imagens de Eletroforese. Revista de Exatas e TECnológicas, 2(1), 08-17.

Sayuri Tahara Amaral, C., de Souza, O., Hilkner de Souza, L., José da Silva, G., \& Noboru Fatori Trevizan, L. (2020). Novos caminhos da biotecnologia: As inovações da indústria 4.0 na saúde humana. Revista Brasileira Multidisciplinar, 23(3), 203-231. https://doi.org/0.25061/2527-2675/ReBraM/2020.v23i3.889

Santos, J., Xavier, M. A. S., Cardoso, L., Nobre, S. A. M., Bacchi, R. R., Cangussu, C. H. C., Almeida, A. C., Leite, L. N., Barreto, N. A. P., \& Xavier, A. R. E. O. (2020). Research Article Identification and molecular analysis of yeasts found in domestic pigeon droppings in Montes Claros, MG, Brazil. Genetics and Molecular Research, 19(1). https://doi.org/10.4238/gmr18521

Soares, L. F. S.; Stein, L. H.; Tieppo, E.; Moro, J. M. S.; Coutinho, M. A., Raittz, R. T.; Marchaukosk, J. N., Iris Hass, Picheth, G. (2010). Análise Eletroforética em Géis Unidimensionais: Nova Abordagem Focada em Inteligência Artificial e Estudo Comparativo de Soluções. In: VI WORKSHOP DE VISÃO COMPUTACIONAL WVC 2010.

Sommerville, I. (2011). Engenharia de Software (9th ed.). Person Prentice Hall.

Telles, E. S., Barone, D. A. C., \& Da Silva, A. M. (2020). Inteligência Artificial no Contexto da Indústria 4.0. In Workshop sobre as Implicações da Computação na Sociedad. Sociedade Brasileira de Computação. https://doi.org/10.5753/wics.2020.11044

Teixeira, R. L. P., Teixeira, C. H. S. B., Brito, M. L. d. A., \& Silva, P. C. D. (2019). Os discursos acerca dos desafios da siderurgia na indústria 4.0 no Brasil Brazilian Journal of Development, 5(12), 28290-28309. https://doi.org/10.34117/bjdv5n12-016

Tsuchida, S., Umemura, H., \& Nakayama, T. (2020). Current status of matrix-assisted laser desorption/ionization-time-of-flight mass spectrometry (MALDITOF MS) in clinical diagnostic microbiology. Molecules, 25(20), 4775. https://doi.org/10.3390/molecules25204775

Wang, C., Gao, X., Wang, S., \& Liu, Y. (2020). A smartphone-integrated paper sensing system for fluorescent and colorimetric dual-channel detection of foodborne pathogenic bacteria. Analytical and Bioanalytical Chemistry, 412(3), 611-620. https://doi.org/10.1007/s00216-019-02208-z

Zhu, X., Yan, S., Yuan, F., \& Wan, S. (2020). The applications of nanopore sequencing technology in pathogenic microorganism detection. Canadian Journal of Infectious Diseases and Medical Microbiology, 2020, 1-8. https://doi.org/10.1155/2020/6675206 